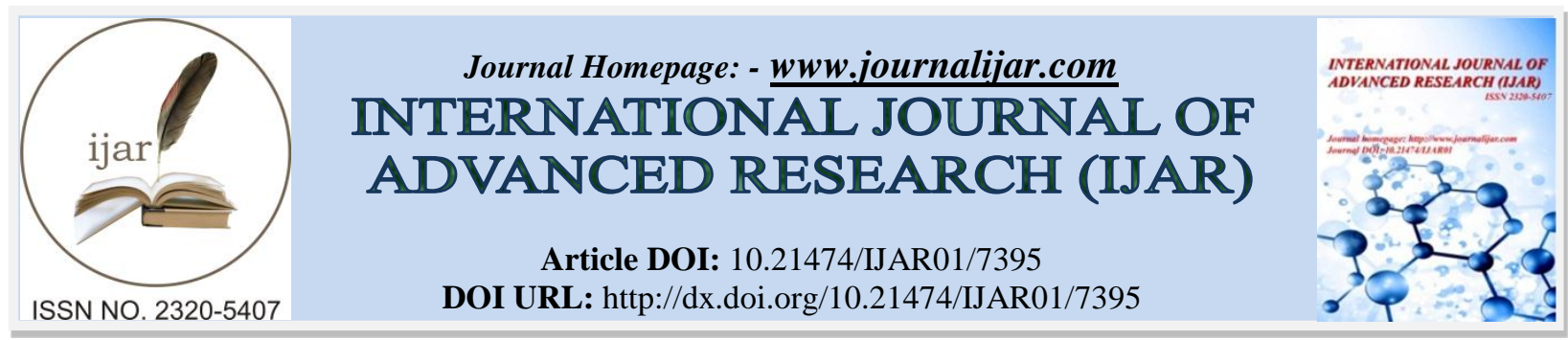

RESEARCH ARTICLE

\title{
HTCC APPROACH FOR PACKAGING MEMS ACCELEROMETER SENSORS AND ASSOCIATED ROIC.
}

Accurex Solutions (P) Ltd., \# 782, $3^{\text {rd }}$ Main, $1^{\text {st }}$ K. S. R. C. Murthy. BEML Layout, $5^{\text {th }}$ Stage, Rajarajeswari Nagar, Bangalore 560 098, India.

\section{Manuscript Info}

Manuscript History

Received: 11 May 2018

Final Accepted: 13 June 2018

Published: July 2018

Keywords:-

MEMS sensors, HTCC, XY

accelerometer, Z Axis accelerometer,

ROIC, QFN.

\section{Abstract}

Problems associated with assembly and packaging of two accelerometer Micro Electro Mechanical Sensors (MEMS) and associated Read Out Integrated Circuit (ROIC) into a single compact package as per customer requirements were discussed, analysed and a High Temperature Co-fired Ceramic (HTCC) solution was suggested.

\section{Introduction:-}

Accelerometer and ROIC Overview:-

MEMS (Micro Electro Mechanical Sensors) inertial devices [1] such as accelerometers and gyros consist moving parts and they often face special handling and packaging challenges. MEMS parts can be sensitive to mechanical shock, especially in unpackaged form and are vulnerable to particulate contamination like residue from wafer sawing etc.

The mechanical motion zone of a MEMS chip need to be protected during singulation with a temporary mask or by wafer-level packaging techniques or by releasing the moving structures after assembly.

However, the most significant packaging challenge is to provide environmental protection that does not restrict sensor chip-level motion. Conventional ceramic or plastic packages used for ASICs (Application Specific Integrated Circuits) or ICs (Integrated Circuits) cannot fullfil these requirements. Designing packages for specific needs of the MEMS-Sensors becomes a necessity [2].

\section{MEMS Pacakge Requirements:-}

The hermeticity debate such as whether we really need a full-hermetic package for inertial devices like accelerometers and gyroscopes continues. Though many other types of MEMS products are not packaged in hermetic enclosures because they require access to the outside world as with ink jet chips and fluidic MEMS products, inertial sensors are somewhat unique and only need electrical I/Os since motion sensing is possible even in a closed package also, subject to provision of adequate space for motion of the sensor components within the package. Thus inertial devices are being hermetically enclosed with cavity designs so that mechanical action is allowed [3]. 
Requirement of integration of associated ROIC for specific sensor further complicates the packaging issues. Location of an ROIC as close as possible to sensor becomes mandatory to avoid parasitics that may affect the precision and accuracy of sensor adversely. This is also a physical necessity for the wirebonds which connect both the components and sensor to prevent shorting during device operation.

Some devices also require internal atmosphere control since moisture and particle contamination can be damaging. Getters (trap moisture and particles), lubricants, or anti-stiction agents may also be added to the package to prevent wear, degradation, or stiction [4]. Stiction, a combination of sticking and friction, is a common problem in MEMS sensors with moving structures. Stiction occurs when smooth, planar surfaces make contact and become permanently locked together by short-range atom forces. Since MEMS devices are so small, these moving parts have a very high area-to-mass ration making stiction likely.

Thus while designing a package for MEMS modules one has to look into all these requirements.

\section{Commercial Pacakge Designs:-}

Analog Devices, Inc., Cambridge, MA, did much of the pioneering work in this field and enjoys a leadership position in the accelerometer area. But there is substantial competition [5].

Freescale also has a long history in motion sensors and launched 3-axis motion sensor products a few years back. OKI, MemSense, Hitachi, Kionix and STMicroelectronics also have offered 3-axis accelerometers.

Most of these devices are packaged in small QFN format. The smallest package is $5 \mathrm{~mm} \times 5 \mathrm{~mm} \times 1.2 \mathrm{~mm}$ offered by Kionix, but competitors have designs that are only slightly larger [6,7].

Fig. 1 shows several QFN (Quad Flat pack with No leads) MEMS packages. Most of them use ceramic hermetic packages, at least for now. The simple QFN has reduced the cost over earlier ceramic cavity style packages that had accounted for more than half of the total component cost.

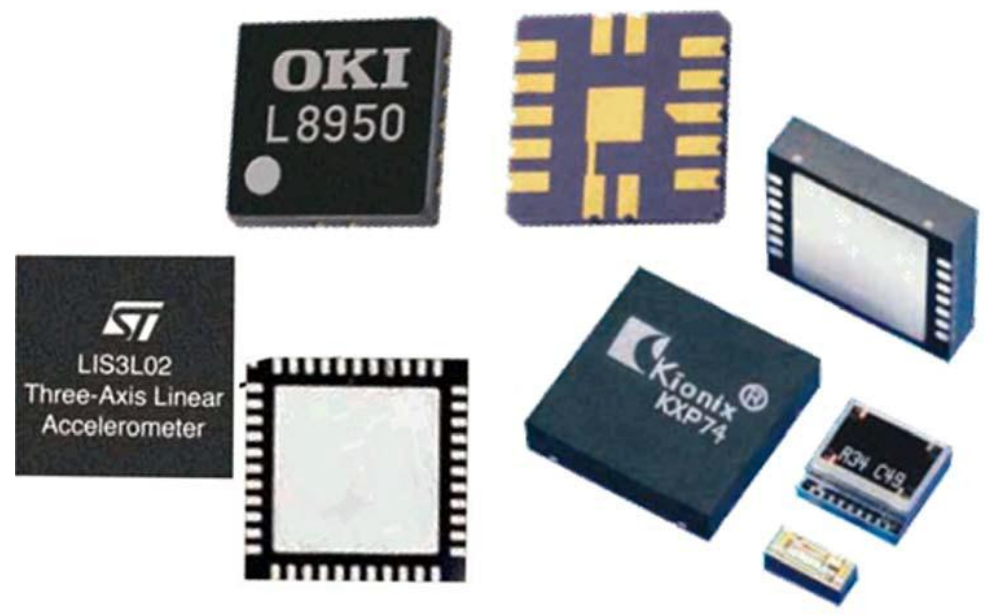

Fig. 1:-Packaged MEMS Accelerometers

Sources: ST-Microelectronics, OKI Electric Industry, Kionix

MEMS device is often capped at wafer-level so that the motion zone is hermetically enclosed [8,9]. The device thus is protected from both particulate contamination and moisture. The bonded silicon caps are specially singulated so that they are smaller than the chip allowing bonding pad access. The capped MEMS device can now be handled more like any ordinary electronic chip. 


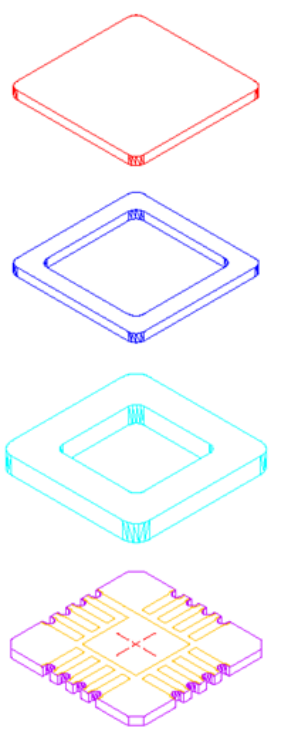

Cover

Metal Seal Ring

\section{Lower Glass/Ceramic}

Fig. 2:-General Packaging Flow for MEMS Modules with hermetic sealing

The capped device can subsequently be packaged either in plastic or ceramic. The capped device is attached along with ROIC and wire bonded to the ceramic cavity package. Finally fully hermetic sealing is achieved through sealing by ceramic or combo coverlid using AuSn preforms or low temperature glass preforms. The general flow is highlighted in Fig. 2.

Main features of this technology include:-

1. High Temperature Co-fired Ceramic (HTCC) Technology

2. Low Temperature Glass Seal Technology

1. Flat or Cup-shaped Ceramic Lids

2. Any Standard Package can be Hermetic

3. MIL-STD-883 Fine and Gross Leak Hermetic

4. Capable of Passing HAST / Autoclave / Pressure Cooker Tests

The present paper describes a design approcah to relaize a pacakge meeting the requirements of one of the customers. Customer has fabricated an XY Accelerometer, a Z-Accelerometer and an associated ROIC and wanted to integrate all these into a single hermetic package that can pass through MIL-STD specifications. The paper describes a design approach that can be physically achieved through HTCC (High Temperature Co-fired Ceranmic) Technology [10].

Details of ROIC and Sensor chips fabricated at Customer's MEMS fab:-

Details of ROIC chip and sensor devices fabricated by the Customer at his MEMS Fab are given below in Table I and shown in Fig.3, Fig.4 and Fig.5 for ROIC, XY Sensor and Z-Sensor respectively :

Table I:-Details of Customer chips and sensors

\begin{tabular}{|c|c|c|c|c|c|c|c|}
\hline \multirow[t]{2}{*}{ Sl.No. } & \multirow[t]{2}{*}{ Device } & \multirow[t]{2}{*}{ form } & \multicolumn{3}{|c|}{ Dimensions (mm) } & \multirow{2}{*}{$\begin{array}{l}\text { No pin-outs in } \\
\text { final package }\end{array}$} & \multirow[t]{2}{*}{ Remarks } \\
\hline & & & $\mathbf{L}$ & $\mathbf{w}$ & $\mathbf{t}$ & & \\
\hline 1 & ROIC ASIC & Die & 4.5 & 4.5 & 0.7 & 92 & $\begin{array}{l}40(\text { Top) }+40 \text { (Left) }+12 \\
\text { (Bottom) } \\
\text { Note-1 }\end{array}$ \\
\hline 2 & $\mathrm{X}, \mathrm{Y}$ - Sensor & Die & 2.1 & 3.8 & 0.7 & 0 & Note-2 \\
\hline 3 & Z-Sensor & Capped Die & 3.5 & 4.5 & 1.4 & 0 & Note-3 \\
\hline
\end{tabular}


1. Note-1: 14 pins on right side are to be bonded to XY-Sensor while 5 pins bottom side are to be connected to Zsensor

2. Note-2: Total 14 pads on left side. None of the pads are connected to package pins. All the die pads are to be connected to respective die pads of ROIC

3. Note-3: Total 5 pads on bottom side and all the pads are to be connected to 5 corresponding bond pads on ROIC die (Bottom side)

\section{ROIC Details:-}

Top - 40 pads at 90 micron pitch

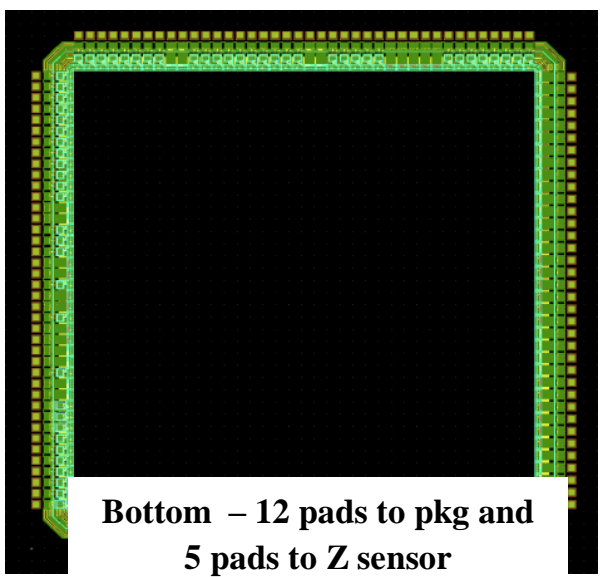

Die details:-Length

Width

Thickness

XY Sensor Details:-

Left - 14 pads

Die details:-Length

Width

Thickness
$4.5 \mathrm{~mm}$

$4.5 \mathrm{~mm}$

$0.7 \mathrm{~mm}$

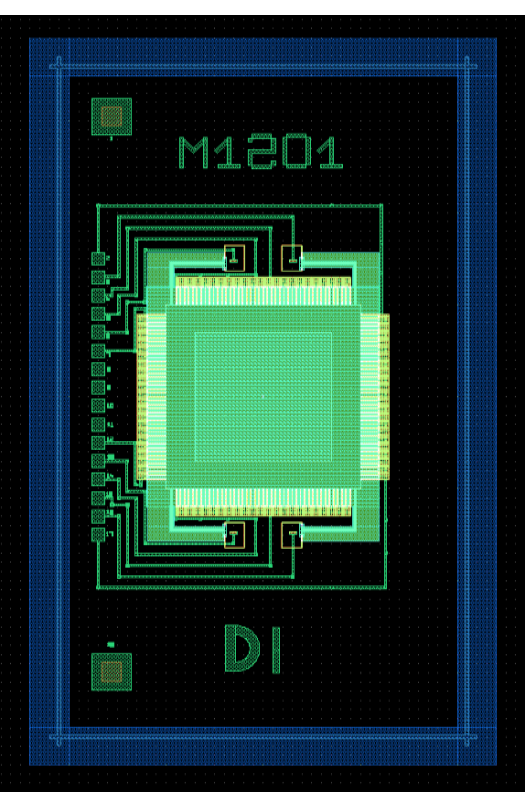

Fig. 4:-MEMS XY Sensor chip

$2.1 \mathrm{~mm}$

$3.8 \mathrm{~mm}$

$0.7 \mathrm{~mm}$
Right - 14 pads

To XY sensor 


\section{Z Sensor Details:-}

Top - 5 pads

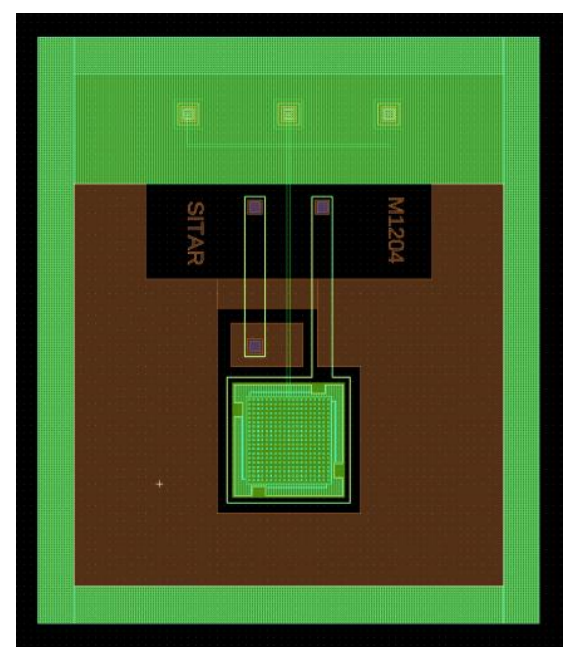

Fig. 5:-MEMS Z - Sensor chip
Die details:-Length

Width

Thickness
$3.5 \mathrm{~mm}$

$4.5 \mathrm{~mm}$

$1.4 \mathrm{~mm}$

MCM (Multi Chip Module) Approach:-

Based on the details provided by the customer an MCM - Multi Chip Module design with layout as indicated in Fig. 6 was proposed.

The layout takes care of design criterea such as minimum die spacing allowed and alignment of bonding pads among ROIC and sensor chips.

\section{Constraints for Customer Sensor Integration:-}

1. ROIC chip has a very high pinout of 92 which is uncomparable with sensors available in the market (maximum 32).

2. Bonding pads are unevenly distributed 40 on top 40 on left 12 on bottom. This makes it difficult to try any other die layouts such as die stack.

3. Individual dies are also quite large - larger than even sensor packages available commercially.

4. Also dies are to be located at specific coordinates to align for proper die to die wire bonding between ASIC and XY Sensor and ASIC and Z Sensor. This practically makes the MCM pad size $7.1 \mathrm{~mm} \times 9.0 \mathrm{~mm}$. Due to capping of Z-Sensor, package height gets decided by height of this sensor which is about $1.4 \mathrm{~mm}$. 


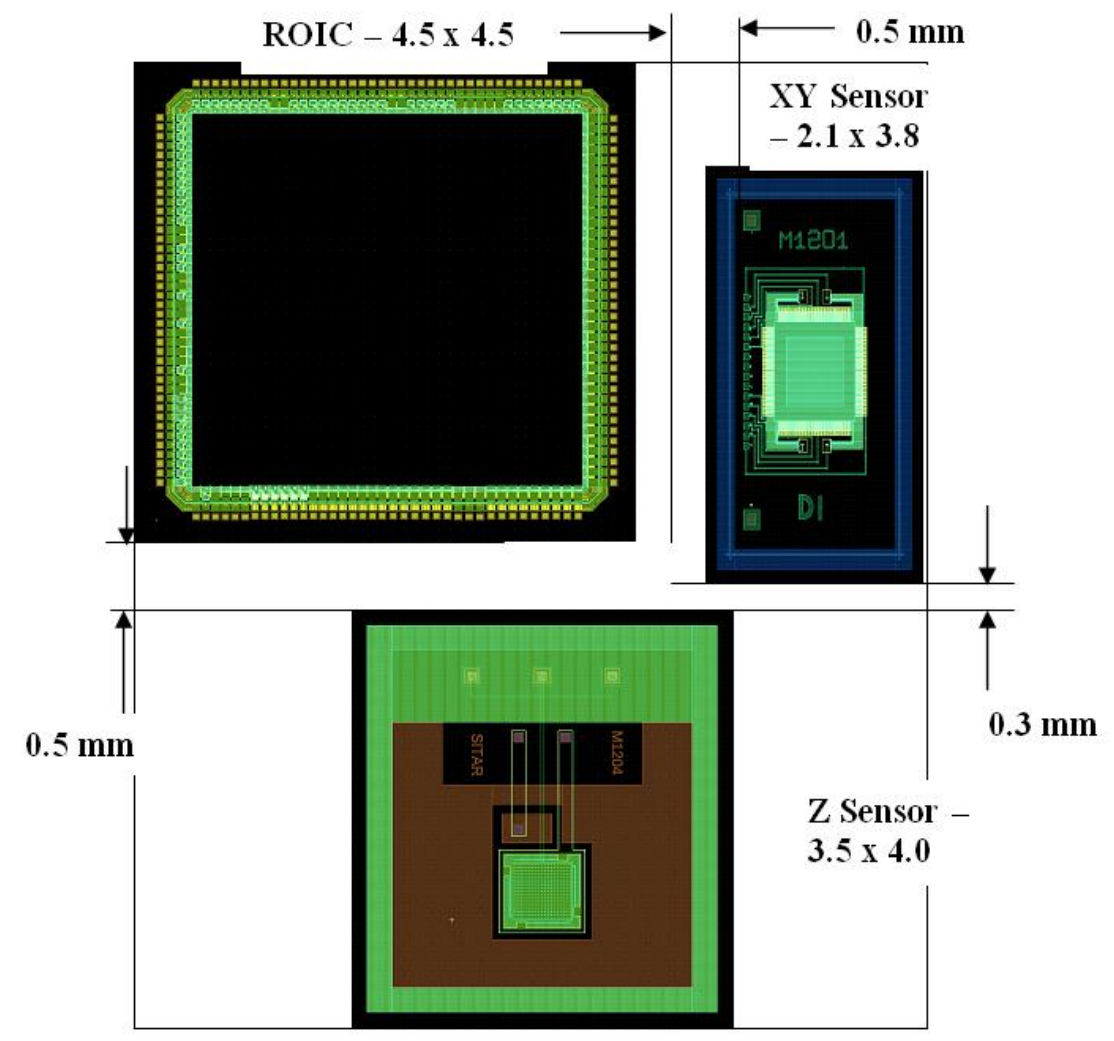

Fig. 6:-3-Chip MCM - Die layout and Total MCM pad area of $7.1 \mathrm{~mm}$ x $9.0 \mathrm{~mm}$

In view of this it is proposed that only solution for any of the above combinations will be keeping the dies side by side as shown in Fig.6 and there will not be much change in final package dimensions.

Wire bonding and Packaging diagrams:-

Based on the proposed 3-chip MCM Layout above, following tentative wire bonding and packaging diagrams were drawn.

Proposed wire bonding diagram for Customer Sensor MCM:-

Tentative wire bonding diagram for the 3-chip module is shown in Fig. 7. 


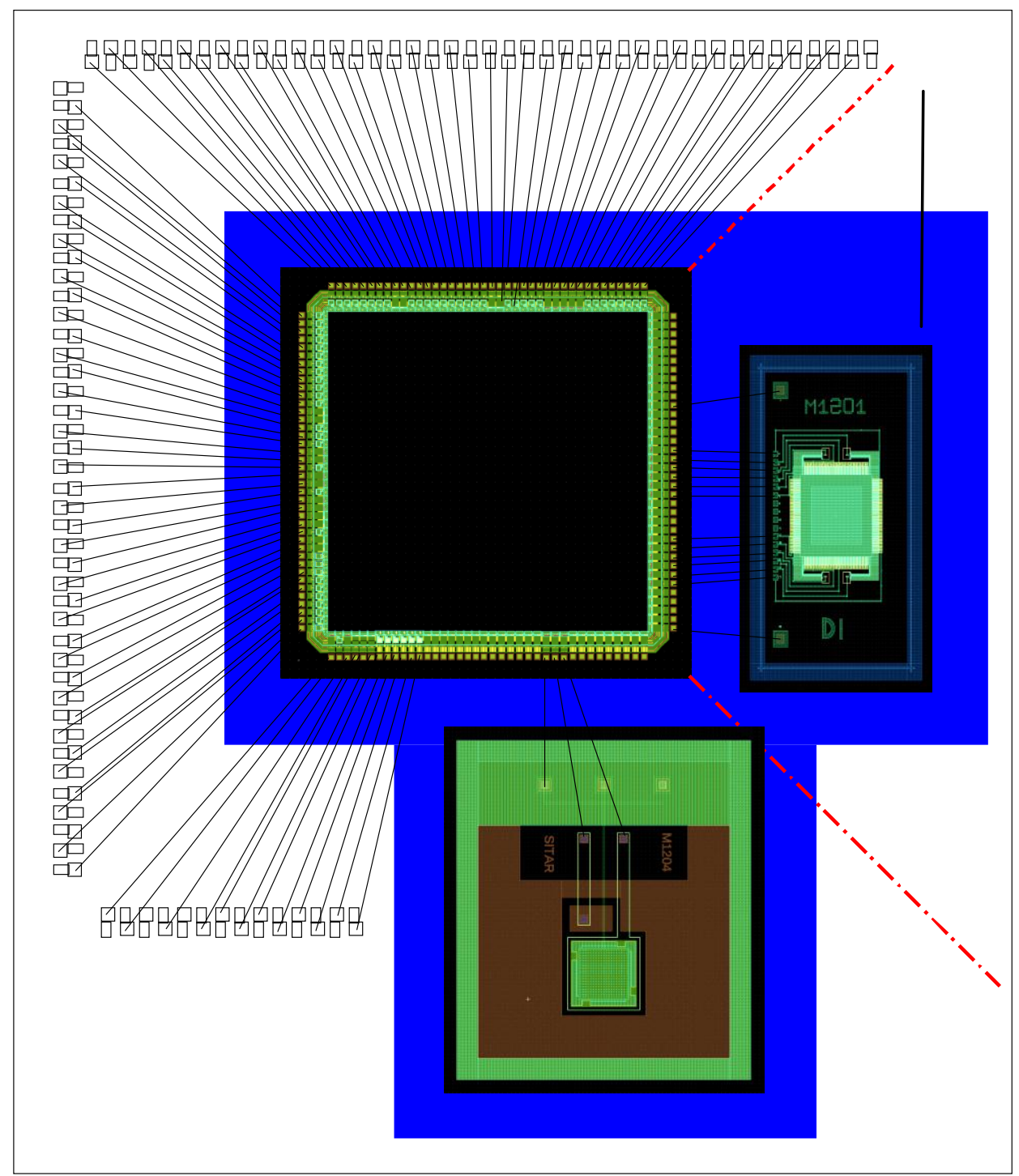

Fig. 7:-Tentative wire bonding diagram for 3 - Chip MCM

\section{Salient Features of Wire Bonding layout:-}

1. The Customer Sensor configuration is unique and there is no standard package which can meet all the requirements of this configuration

2. It is mandatory that a custom made package is to be designed and developed optimizing all the parameters and minimizing the parasitics.

3. State of the art package with die pad, size, pitch and configuration (layout) has been selected as shown in Fig. 8. 

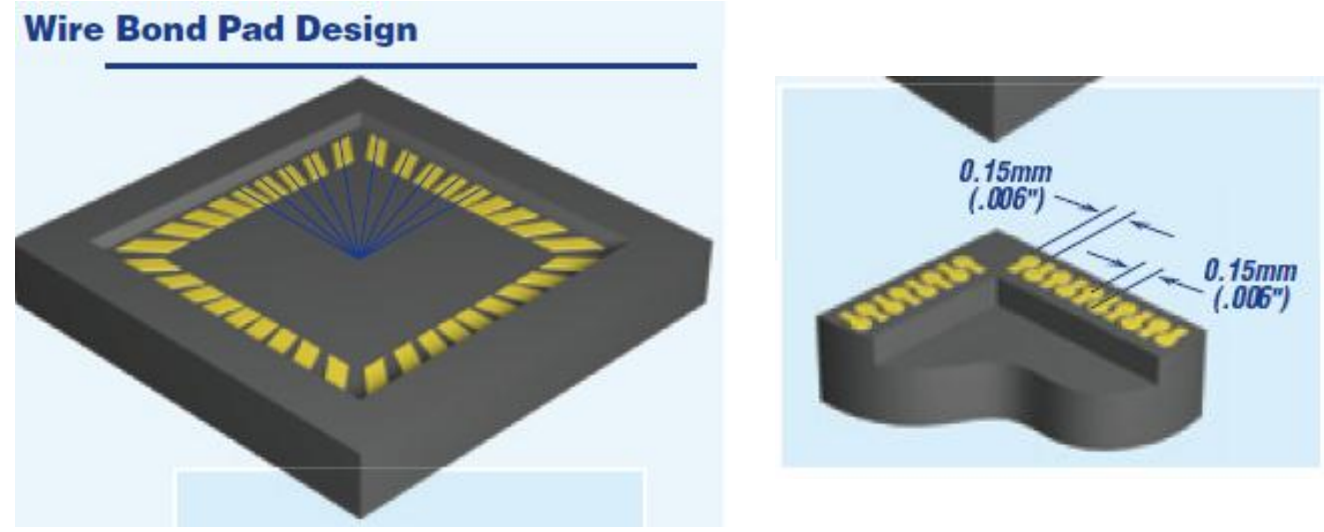

Fig. 8:-Tentative package drawing for 3 - Chip MCM:

1. Die pad size: 150 microns

2. Pad pitch: 150 microns

3. 2 extra die pads are added on all three sides to avoid the problems of wire crossing. This makes total package pin-outs $92+6=98$

Salient Features of Package:-

Appropriate cavity to be developed to house all the three chips at respective coordinates as shown in Fig 9 below:

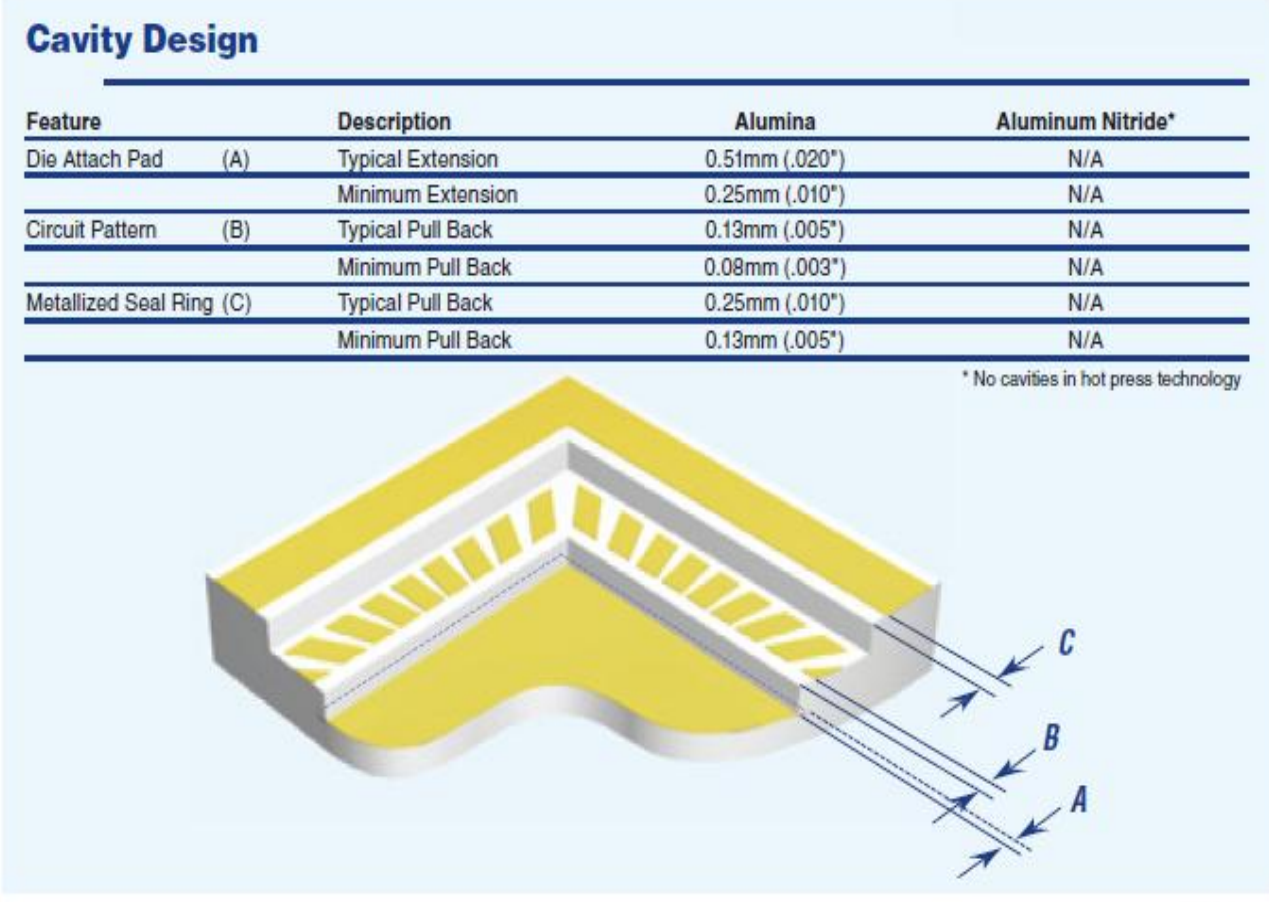

Fig. 9:-Cavity with details of surrounding bonding pads

All the die pads are to be brought out as pin-outs as indicated below in Fig 10, through vertical interconnections: 


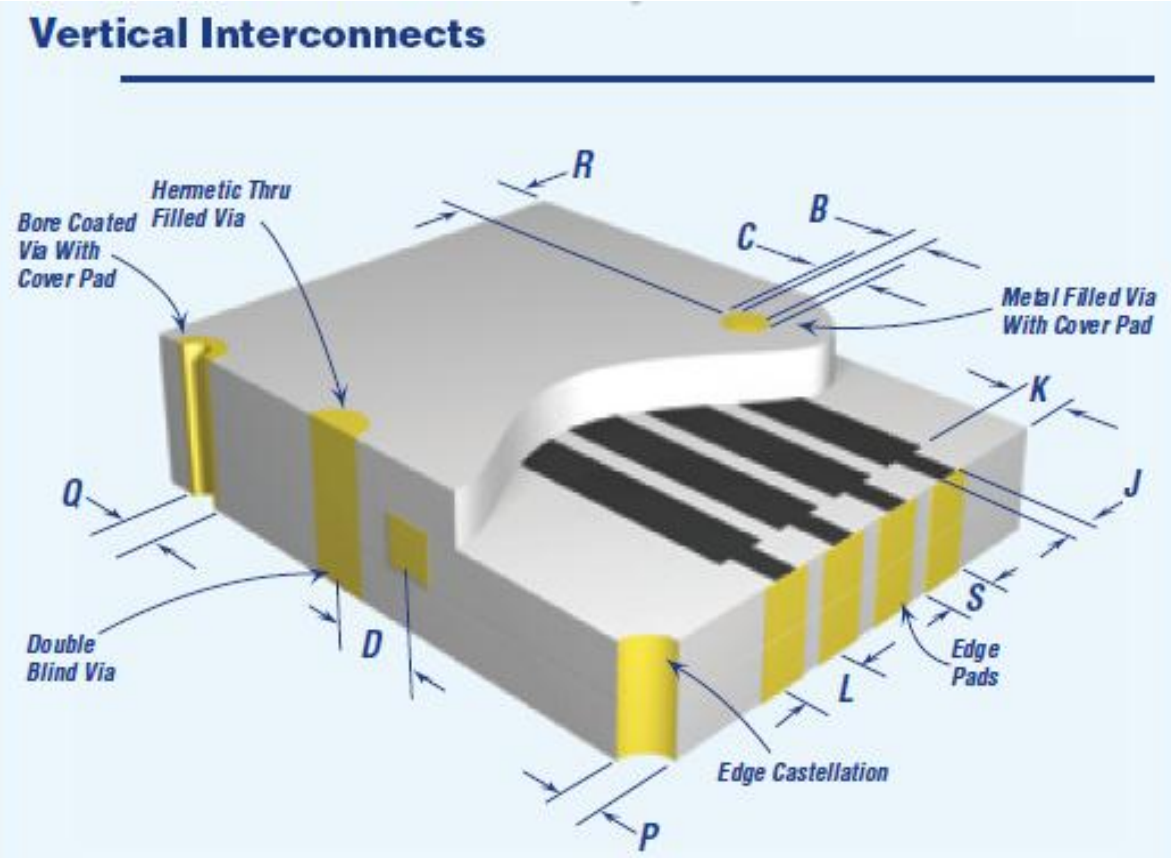

Fig. 10:-pin-out details through castellation

Design guidelines for structural parameters and for vertical interconnects are described in Table II and Table III respectively.

Table II:-Design guidelines for Structural Parameters

\section{Structural Parameters}

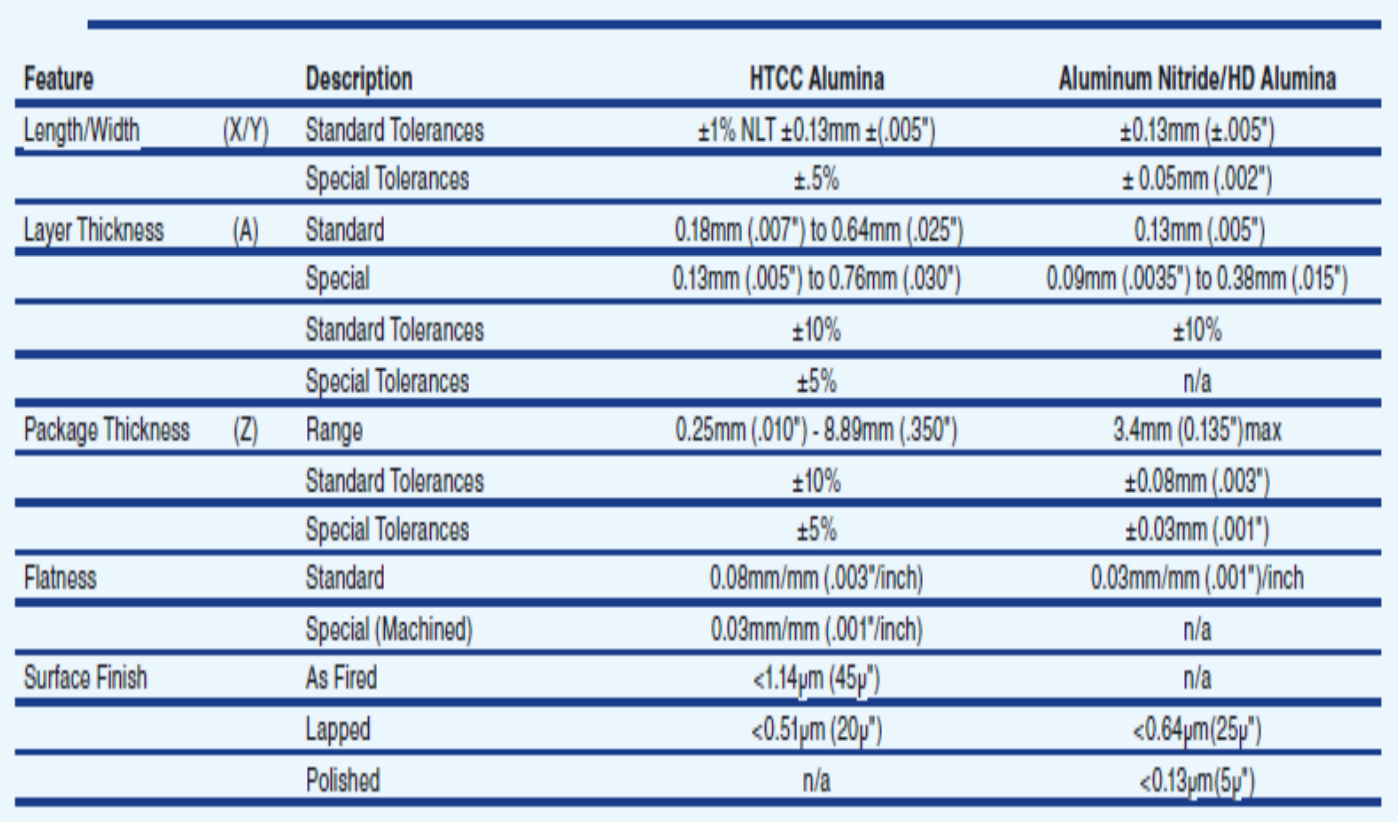


Table III:-Design guidelines for Vertical Interconnects Vertical Interconnects

\begin{tabular}{|c|c|c|c|c|}
\hline Feature & & Description & HTCC Alumina & Aluminum Nitride/HD Alumina \\
\hline \multirow[t]{7}{*}{ Filled Via } & (B) & Diameter Range & $0.10 \mathrm{~mm}\left(.004^{\prime}\right)-0.51 \mathrm{~mm}\left(.020^{\circ}\right)$ & $0.13 \mathrm{~mm}\left(.005^{\circ}\right)-0.51 \mathrm{~mm}\left(.020^{*}\right)$ \\
\hline & (C) & Cover Pad dia (Internal) & Via dia + 0.05mm (.002") & Via dia $+0.05 \mathrm{~mm}\left(.002^{*}\right)$ \\
\hline & (C) & Cover Pad dia (External) & Via dia + $0.13 \mathrm{~mm}\left(.005^{\prime \prime}\right)$ & Via dia $+0.38 \mathrm{~mm}\left(.015^{\prime \prime}\right)^{*}$ \\
\hline & (D) & Via-to-Via Centerline & $0.30 \mathrm{~mm}\left(.012^{2}\right)$ Min. & $0.38 \mathrm{~mm}\left(.015^{\prime \prime}\right)$ Min. \\
\hline & (R) & Via-to-Edge (Standard) & $w=t+v($ web $=$ thickness + via diameter $)$ & $0.25 \mathrm{~mm}\left(.010^{\prime \prime}\right)$ \\
\hline & & Via-to-Edge (Sawed Edge) & $0.20 \mathrm{~mm}\left(.008^{\prime \prime}\right)$ Internal Via & $0.20 \mathrm{~mm}\left(.008^{\prime \prime}\right)$ Internal Via \\
\hline & & Via-to-Edge (Sawed Edge) & 0.00 Split Via (see page 11) & $\mathrm{n} / \mathrm{a}$ \\
\hline \multirow[t]{3}{*}{ Bore Coated Via } & (Q) & Diameter Range & $0.30 \mathrm{~mm}\left(.012^{n}\right)-0.64 \mathrm{~mm}\left(.025^{*}\right)$ & $\mathrm{n} / \mathrm{a}$ \\
\hline & & Cover Pad Diameter & Hole dia $+0.25 \mathrm{~mm}\left(.010^{*}\right)$ & $n / a$ \\
\hline & (P) & Castellation Radius (Typical) & $0.20 \mathrm{~mm}\left(.008^{\circ}\right)$ & $n / a$ \\
\hline \multirow[t]{4}{*}{ Edge Metallization } & (L) & Centerline & $0.64 \mathrm{~mm}\left(.025^{\prime \prime}\right)$ Min. & $\mathrm{n} / \mathrm{a}$ \\
\hline & (J) & Circuit Neckdown (Range) & $0.13 \mathrm{~mm}\left(.005^{\prime}\right)$ to Width of Edge Metal & $\mathrm{n} / \mathrm{a}$ \\
\hline & $(\mathrm{K})$ & Pullback From Edge & $0.51 \mathrm{~mm}\left(.020^{\circ}\right)$ (TYP) $0.25 \mathrm{~mm}\left(.010^{\circ}\right)$ Min. & n/a \\
\hline & (S) & Minimum Pad Width & $0.20 \mathrm{~mm}\left(.008^{\prime \prime}\right)$ & $n / a$ \\
\hline
\end{tabular}

\section{Final Package Information:-}

The final package dimensions are expected to be as shown in Fig. 11 while charecteristics are given in Table IV. General package top view, bottom pads, seal ring on the top for hermetic sealing and rooting of interconnections in inner layers of HTCC are shown in Fig.12 and cross sectional views in Fig.13.

Table IV:-Final specs of proposed package

\begin{tabular}{|l|l|}
\hline Characteristics & Specifications \\
\hline Package Type & Ceramic HTCC \\
\hline Number of Pins & 98 \\
\hline Number of NC (No connection pins) & 6 out of 98 \\
\hline Weight & $5.0-10.0$ grams \\
\hline
\end{tabular}

\section{Technical details in relaizing the package:-}

Major Process steps:-

1. Package Design and fabrication of package through HTCC Technology

2. Die bonding of ROIC with Silver epoxy on die pad for ROIC

3. Curing Conditions: 150C, 15 minutes in convection oven

4. Wire Bonding of ROIC with gold wire

5. Bonding: Thermosonic ball bonding

6. Gold Wire dia: 0.7 mil dia (17.5 micron)

7. Inspection and Preliminary electrical check for opens and shorts

8. Wire bond pull test

9. Functional testing of ROIC

10. Die bonding of XY Sensor Dispensing Silver epoxy on die pad for XY Sensor

11. Die Curing Conditions: 150C, 15 minutes in convection oven 


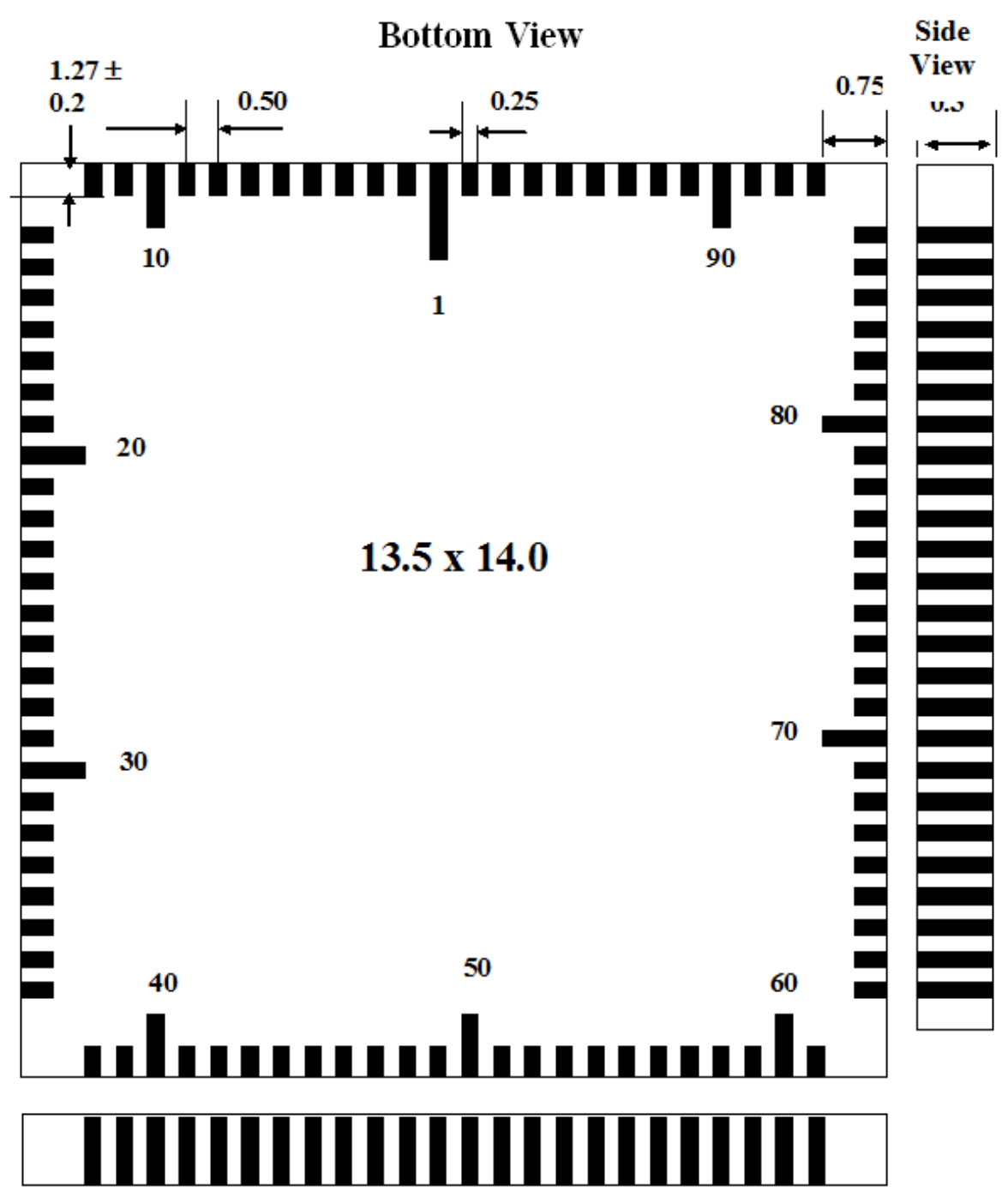

Fig. 11:-Final pin-out details through castellation

1. Wire bonding XY Sensor

2. Wire: 0.7 mil dia (17.5 micron) Au wire

3. Bonding: Gold wire wedge-wedge bonding

4. Gold Wire dia: 0.7 mil dia (17.5 micron)

5. Work Holder Temperature: $115 \mathrm{C}$

6. Wire bonding - Thermosonic

7. Functional testing of XY Sensor

8. Die bonding of $Z$ Sensor

9. Dispensing Silver epoxy on die pad for Z Sensor

10. Placement of die 


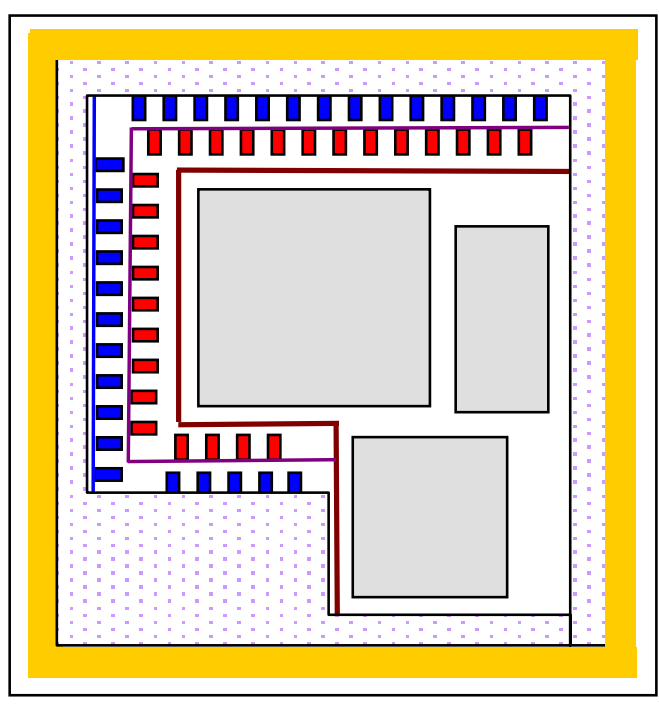

[a]

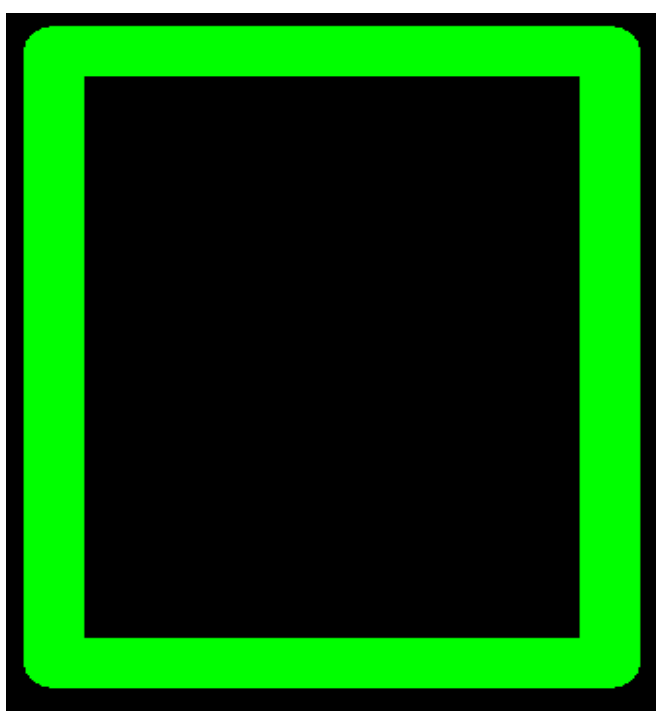

[c]

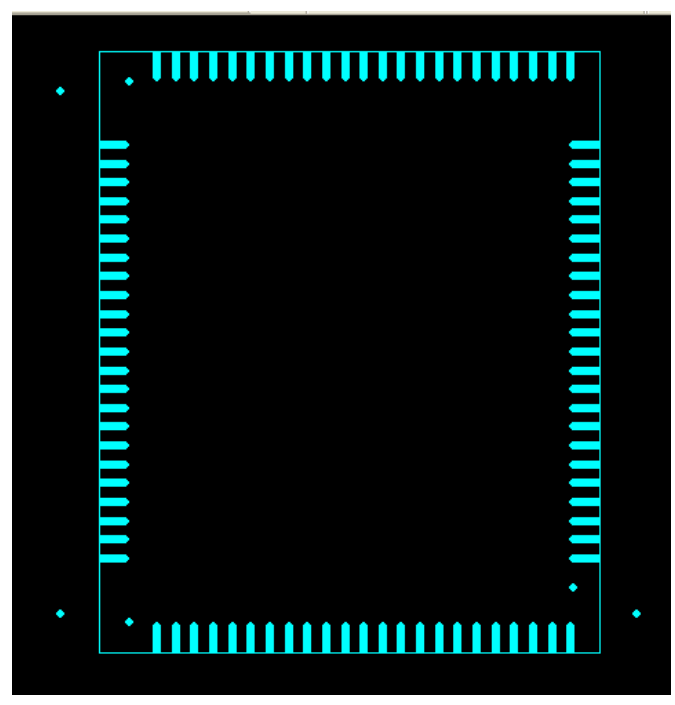

[b]

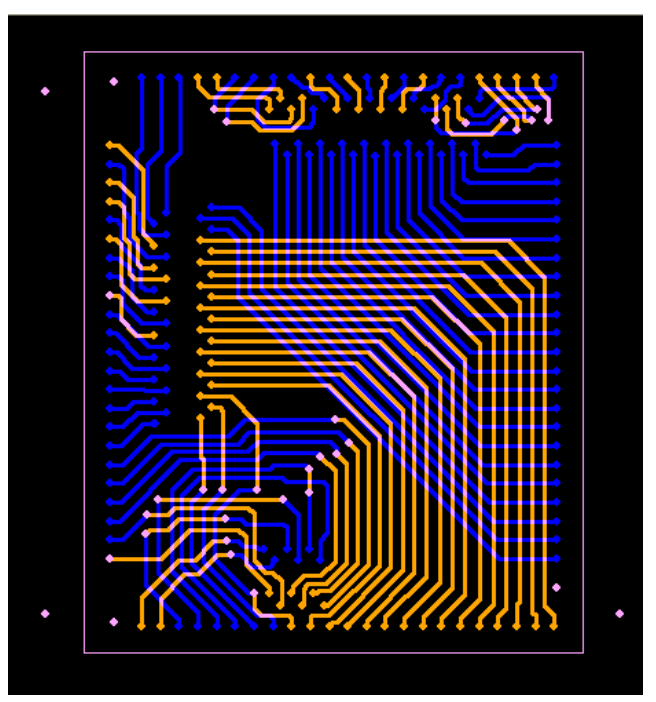

[d]

Fig. 12:-Generic view of the final package (a) View from top with lid not sealed (b) Bottom pad view (c) Seal ring on the top for hermetic sealing (d) Rooting of interconnections in inner layers of HTCC

1. Die Curing Conditions: $150 \mathrm{C}, 15$ minutes in convection oven

2. Wire bonding $\mathrm{Z}$ Sensor

3. Wire: 0.7 mil dia (17.5 micron) Au wire

4. Bonding: Wedge bonding

5. Gold Wire dia: 0.7 mil dia (17.5 micron)

6. Functional testing of $\mathrm{Z}$ Sensor testing

7. Lid sealing and marking

8. Seal integrity testing

9. Screening and Reliability Tests 


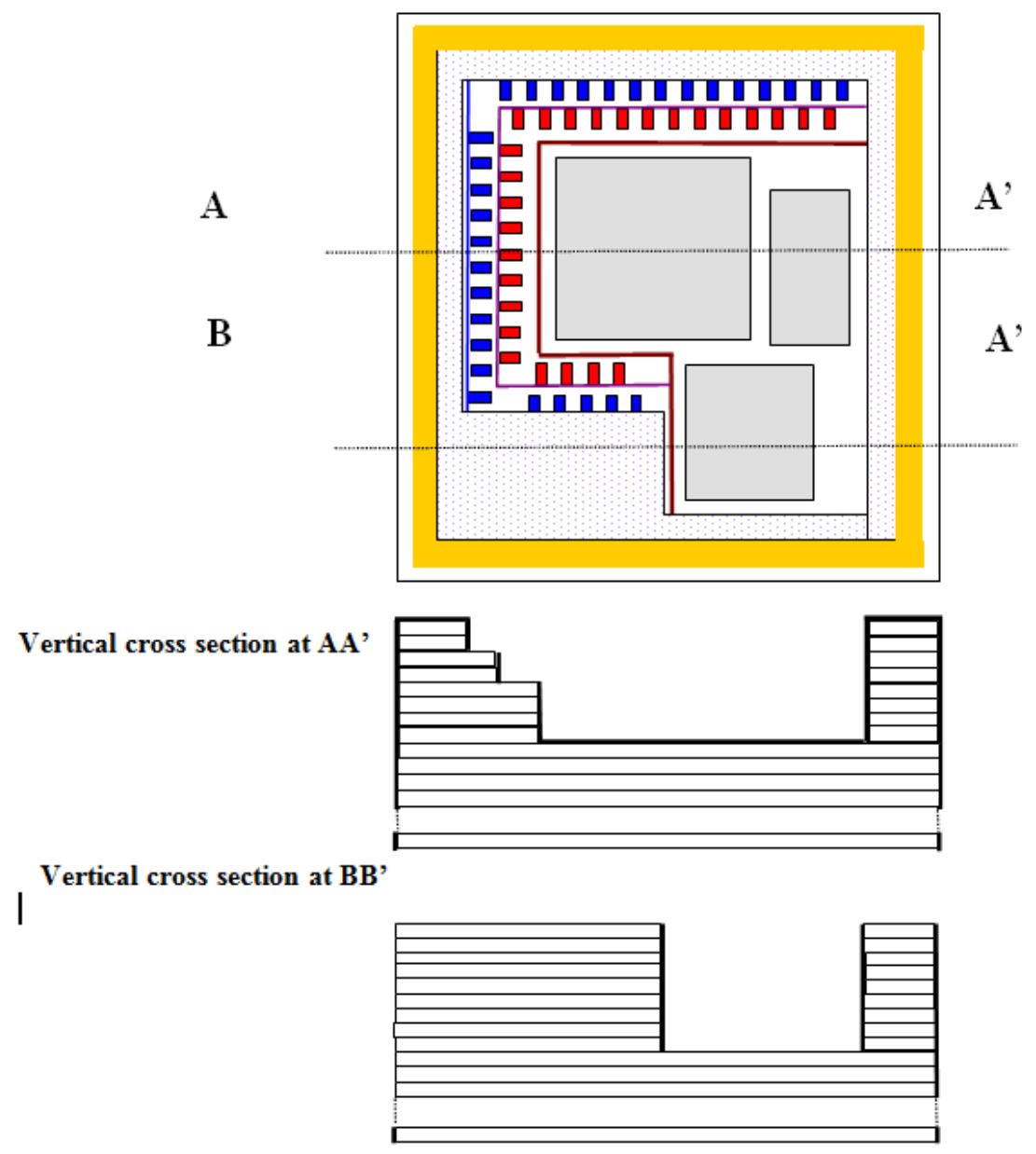

Fig. 13:-Cross sectional views (not to scale) of the package

Note:-

1. XY Sensor and Z Sensor both have moving structures and hence need to be handled cautiously

2. Wire bondings should be as short as possible and loop heights should be as low as possible since longer wire bonds are likely to fail when subjected to shaker table test. Al-Al wedge bonds were found to withstand better.

3. Hence trials are to be carried out both with $\mathrm{Au}-\mathrm{Au}$ wedge bonding and $\mathrm{Al}-\mathrm{Al}$ wedge bonding between sensor and ROIC before freezing the cvonfiguration.

Wafer - Capping Method for Z-Sensor:-

First stack:-

Reactive $\mathrm{SiO} 2-\mathrm{SiO} 2$ Wafer Bonding

Reactive Bonding

Second stack:-

First stack Top - Si with gold pattern

Third wafer Pure Si

Bonding- Au-Si eutectic in 10e-4 vacuum at 350C-400C

Fig. 14 and Fig. 15 show the Top view and side view of the stack while Fig. 16 shows how the sensor looks after completion of process except for partila dicing of top cap to expose the bonding pads. 


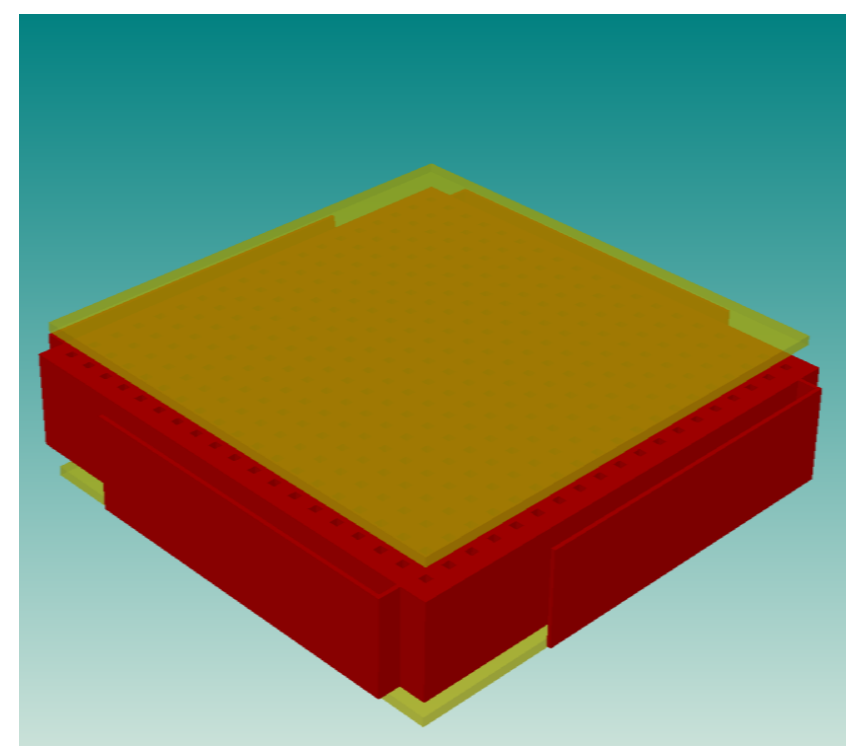

Fig. 14:-3-D Top View of the stack

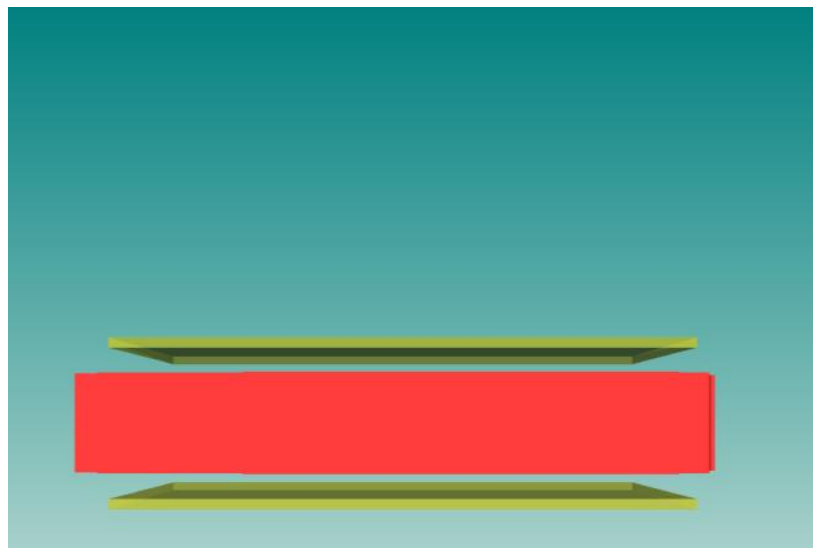

Fig. 15:-3-D Side view of the stack

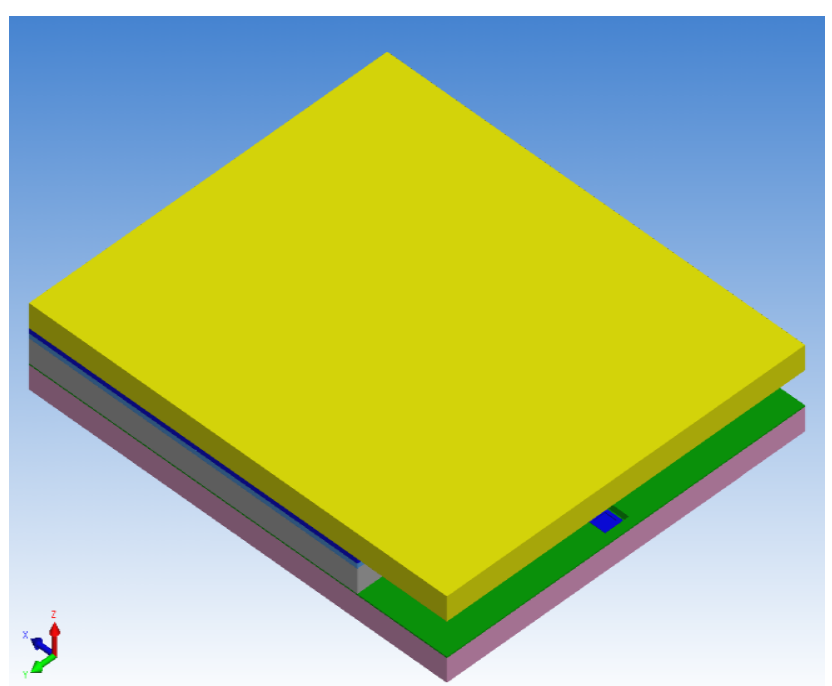

Fig. 16:-After Wafer-3 bonding with wafer 1,2 stack with Gold to Silicon eutectic bonding 
Sensor thickness will be equal to [die thickness + top wafer thickness + bottom wafer thickness] 1.7 to $2.0 \mathrm{~mm}$ Package height after lid sealing will be approximately $4.0 \mathrm{~mm}$

As per the request of the customer, the proposed package was compared with commercially available packages for similar sensors as indicated in Table $\mathbf{V}$.

pin

It was pointed out to the customer that in view of large pine count of ROIC, it would be practically impossible to realize a module with size comparable to commercial packages.

Table V:-Comparison of Customer Sensor Modules with Commercial Modules

\begin{tabular}{|c|c|c|c|c|}
\hline Sl.No. & $\begin{array}{l}\text { Accelerometer Make } \\
\text { and number }\end{array}$ & Spec & MCM Description & $\begin{array}{c}\text { Pkg style \& Size } \\
\text { LxWxT } \\
\text { in mm }\end{array}$ \\
\hline 1 & $\begin{array}{l}\text { Bosch, BMA140, } \\
\text { Triaxial, analog } \\
\text { acceleration sensor }\end{array}$ & $\begin{array}{l} \pm 4 \mathrm{~g} \\
-40 \mathrm{C} \text { to }+ \\
85 \mathrm{C}\end{array}$ & $\begin{array}{l}2 \text { chip } \\
\text { 1. sensor - Hermetically sealed by } \\
\text { bulk micro machined cap } \\
\text { 2. CMOS ASIC }\end{array}$ & $\begin{array}{l}12 \text { pin Plastic LGA } \\
3 \times 3 \times 0.9\end{array}$ \\
\hline 2 & $\begin{array}{l}\text { Bosch, BMA140, } \\
\text { Triaxial, analog } \\
\text { acceleration sensor }\end{array}$ & $\begin{array}{l} \pm 4 \mathrm{~g} \\
-40 \mathrm{C} \text { to }+ \\
85 \mathrm{C}\end{array}$ & $\begin{array}{l}\text { 2 chip } \\
\text { 1. sensor - Hermetically sealed by } \\
\text { bulk micro machined cap } \\
\text { 2. CMOS ASIC }\end{array}$ & $\begin{array}{l}16 \text { pin Plastic LGA } \\
4 \times 4 \times 0.9\end{array}$ \\
\hline Sl.No. & $\begin{array}{l}\text { Accelerometer Make } \\
\text { and number }\end{array}$ & Spec & MCM Description & $\begin{array}{c}\text { Pkg style \& Size } \\
\text { LxWxT } \\
\text { in mm }\end{array}$ \\
\hline 3 & $\begin{array}{l}\text { Analog make } \\
\text { ADXL312, Digital } \\
\text { accelerometer }\end{array}$ & $\begin{array}{l} \pm 1.5 \mathrm{~g} \\
\pm 3 \mathrm{~g} \\
\pm 6 \mathrm{~g} \\
\pm 12 \mathrm{~g} \\
\\
-40 \mathrm{C} \text { to } \\
+105 \mathrm{C}\end{array}$ & $\begin{array}{l}2 \text { chip } \\
\text { 1. sensor } \\
\text { 2. CMOS ASIC }\end{array}$ & $\begin{array}{l}32 \text { pin LFCSP } \\
\text { (Lead Frame CSP) } \\
5 \times 5 \times 1.45\end{array}$ \\
\hline 4 & $\begin{array}{l}\text { Kionix make } \\
\text { KXPS5 }\end{array}$ & $\begin{array}{l} \pm 3 \mathrm{~g} \\
-40 \mathrm{C} \text { to }+ \\
85 \mathrm{C}\end{array}$ & $\begin{array}{l}\text { 2 chip } \\
\text { 1. sensor - Hermetically sealed by } \\
\text { bulk micro machined cap with } \\
\text { glass frit } \\
\text { 2. CMOS ASIC }\end{array}$ & $\begin{array}{l}14 \text { pin LGA Plastic } \\
5 \times 3 \times 0.9\end{array}$ \\
\hline 5 & ST make LSM303DLH & $\begin{array}{l} \pm 2 \mathrm{~g} \\
\pm 4 \mathrm{~g} \\
\pm 8 \mathrm{~g}-30 \mathrm{C} \\
\text { to }+85 \mathrm{C} \\
\end{array}$ & $\begin{array}{l}\text { 3 chip } \\
\text { 1. Acceleration sensor } \\
\text { 2. magnetic field sensor } \\
\text { 3. CMOS ASIC }\end{array}$ & $\begin{array}{l}28 \text { pin LGA } \\
5 \times 5 \times 1.0\end{array}$ \\
\hline 6 & Customer & $\pm 100 \mathrm{~g}$ & $\begin{array}{l}3 \text { chip } \\
\text { 1. XY Acceleration Sensor } \\
\text { 2. Z Acceleration Sensor } \\
\text { 3. CMOS ASIC }\end{array}$ & $\begin{array}{l}98 \text { pins } \\
\text { custom ceramic } \\
\text { Hermetic SM package } \\
13.5 \times 14.0 \times 4.0\end{array}$ \\
\hline
\end{tabular}

\section{Conclusions:-}

When a customer approached with a requirement for packaging two MEMS acceleration sensors and one associated ROIC into a single compact module that can pass through the MIL Screening tests, the requirement was analysed from various angles and finally a solution was suggested using HTCC technology. 


\section{References:-}

1. Analog Devices,'The Five Motion Senses: Using MEMS Inertial Sensing to transform Applications', http://www. analog.com/media/en/technical-docu-mentation/white-papers/The_Five_Motion_Senses.pdf

2. Jeron J.M.Zaal, Willem D.van Driel and G.Q.Zhang, 'Challenges in the Assembly and Handling of Thin Film Capped MEMS Devices, Sensors 2010, 10, 3989-4001.

3. L.E.Felton, N.Hablutzel, W.A.Webster and K.P.Harney, 'Chip scale packaging of a MEMS accelerometer', 2004 Proceedings. 54th Electronic Components and Technology Conference, LasVegas, USA, 4-4 June 2004

4. Doug Sparks, 'NanoGetters', www. mems-exchange.org/catalog/P3502/file/6b 0193ffd70a/NanoGetters.ppt

5. Analog Devices, www.analog.com/en/ mems-sensors/inertial-s.html

6. LSM303DLH, 'Sensor module: 3-axis accelerometer and 3-axis magnetometer', Doc ID 16941 Rev 1, Dec.2009, www.st.com

7. Ken Gileo, 'MEMS Packaging Update, Advance Packaging 2005, MEMS/MOEMS Pacakging Pub.Mc Graw Hill, July 2005, https://mhebooklibra ry.com/doi/book/10.1036/0071455566

8. Steven Nasiri, 'Wafer-Scale Packaging and Integration for Low-Cost MEMS Motion Sensor Products', IWLPC (Wafer-Level Packaging) Conference Proceedings, Pub Sept 17, 2007.

9. K.N.Bhat, A Das Gupta, P.R.S.Rao, N.Das Gupta, E.Bhattacharya, K.Sivakumar, V.Vinoth Kumar, L.Helen Anitha, J.D.Joseph, S.P.Madhavi and K.Natarajan, 'Wafer bonding - A powerful tool for MEMS', Indian Journal of Pure \& Applied Physics, Vol 45, April 2007, p 311-316.

10. AdTech Ceramics, 'Design Guidelines', www.adtechceramics.com/pdf/ AdTech-Ceramics-Design-GuideCapabilities.pdf. 